\title{
An Evidence-Based Approach to Assess the Accuracy of MRI in Diagnosing Rotator Cuff Tears: A Systematic Review and Meta-Analysis
}

\author{
Wen-Fei Li ${ }^{1,}$, Tahir Mehmood Shakir ${ }^{2}$, Yuemei Zhao ${ }^{1}$, Tao Chen $^{3}$, Chen Niu ${ }^{2}$ and Zhanqiu Wang ${ }^{1}$ \\ ${ }^{1}$ Department of Radiology, The First Hospital of Qinhuangdao, Qinhuangdao, Hebei, China \\ ${ }^{2}$ Department of Radiology, First Affiliated Hospital of Xi'An Jiaotong University, Xi'an, Shaanxi, China \\ ${ }^{3}$ Department of Radiology, Xiang yang Central Hospital, Xiangyang, Hubei, China \\ "Corresponding author: Department of Radiology, The First Hospital of Qinhuangdao, 258 Wenhua Road, Qinhuangdao Hebei 066000, China. Email: 591987959@qq.com
}

Received 2018 May 16; Revised 2018 December 12; Accepted 2018 December 29.

\begin{abstract}
Background: A precise preoperative diagnosis is important for the treatment of patients, and the extent of rotator cuff tears will determine the patient's choice of conservative treatment or surgical treatment.

Objectives: This paper was conducted to assess the diagnostic accuracy of magnetic resonance imaging (MRI) in the evaluation of rotator cuff tears.

Materials and Methods: A computerized search using PubMed, EMBASE, Chinese Biomedical databases, Web of Knowledge, and Cochrane Libraries was performed to identify original research studies by two independent reviewers separately.

Results: Eighteen surveys that investigated MRI to diagnose rotator cuff tears were included. Influence factors on the diagnostic accuracy were evaluated using meta-regression analysis. For any rotator cuff tear, the pooled sensitivity and specificity were 0.93 and 0.88 , respectively. Overall, MRI had higher pooled sensitivity (0.87) and specificity (0.93) of full-thickness tears, relative to sensitivity (0.80) and specificity (0.92) of partial tears. In addition, the overall area under the curve (AUC) of MRI for identifying full-thickness tears (96\%) was close to that for any rotator cuff tear, a value that was much higher than for partial tears (86\%). Threshold effects were not significant in this meta-analysis.

Conclusion: After analyzing the results of this study, we demonstrated that MRI had excellent performance regarding the diagnosis of rotator cuff tears. Our study showed that the diagnostic accuracy of MRI in diagnosing full-thickness rotator cuff tear is significantly better than that of partial thickness rotator cuff tears.
\end{abstract}

Keywords: MRI, Rotator Cuff Tear, Meta-Analysis

\section{Background}

Rotator cuff tear is a common cause of shoulder pain (1). The rotator cuff is a sleeve-like structure composed of muscles and their tendons and is the major anatomical structure to maintain shoulder stability (2). A precise preoperative diagnosis is important for the treatment of patients and the extent of rotator cuff tears will determine the patient's choice of conservative treatment or surgical treatment, especially for surgeons to perform an operation procedure (3). Clinically, there are many imaging examinations that can help us diagnose rotator cuff tears, such as ultrasound and magnetic resonance imaging (MRI).

MRI provided detailed and comprehensive information related to various aspects of rotator cuff tears that may be helpful to select the appropriate treatment plan(4). MRI has been considered as a non-invasive method to evaluate full-thickness rotator cuff tears, especially partial thick- ness rotator cuff tears (5-7). Although several studies have reported that MRI has high accuracy for the detection of rotator cuff tears, the results were not uniform. Previous meta-analyses have demonstrated the effectiveness of MRI in the diagnosis of rotator cuff tears $(8,9)$; nonetheless, these studies only assessed English-language publications and retrospective studies.

\section{Objectives}

In this study, we included literatures published in English and Chinese language and analyzed the correlation between factors (field strength, equipment, and language) and the diagnostic performance of MRI. A comprehensive evaluation of the accuracy of MRI in the diagnosis of rotator cuff tears was the purpose of this study. 


\section{Materials and Methods}

\subsection{Search Strategy}

A computerized search using PubMed, EMBASE, Chinese Biomedical databases, Web of Knowledge, and Cochrane Libraries was performed to identify original research studies by two independent reviewers separately. The following terms and medical headings were used: "magnetic resonance imaging", "MRI", "Shoulder", "Shoulder impingement syndrome", "Shoulder joint", "Subacromial impingement", "Rotator cuff", "Tendinopathy”, "Shoulder pain”, "sensitivity”, "specificity”, “falsenegative”, "false-positive”, “diagnosis”, and “accuracy”.

\subsection{Eligibility Criteria for Study Selection}

All the studies were included according to the following criteria: (1) Studies of MRI on the human application to evaluate rotator cuff injury; (2) Studies that used surgical examination as the reference standard; (3) Only relevant articles published in English and Chinese; (4) Truepositive (TP), true-negative (TN), false-positive (FP), and false-negative (FN) values extracted from the raw data; and (5) Number of patients greater than 40. Unpublished data, reviews, case reports, conference abstracts, letters, comments, and editorials were excluded. If there were some overlapping studies, we chose a recent report to avoid data redundancy.

\subsection{Data Collection and Quality Assessment}

Data collection of each study included the following content: publication year, number of patients, age, applied field strength, and MRI technique parameters. The overall TP, TN, FP, and FN values were extracted. The quality of included study was assessed by quality assessment of diagnostic accuracy studies (QUADAS) tool (10). Box 1 shows all items of QUADAS tool.

\subsection{Statistical Analysis}

All data analysis was performed using Meta-DiSc and Stata 11.0 (Stata, College Station, Tex). Two reviewers independently constructed the $2 \times 2$ tables. Sensitivity (SEN), specificity (SPE), positive and negative likelihood ratio, and diagnostic odds ratio (DOR) with their 95\% confidence intervals (CI) were calculated and analyzed. We also calculated the summary receiver-operating characteristic (SROC). We also used $\mathrm{I}^{2}$ to test the study variation attributed to heterogeneity. Influence factors on the diagnostic accuracy were evaluated using meta-regression analysis (least squares weighted by inverse variance) (11). The parameters listed in Table 1 were used as covariates. Publication bias was assessed using the Deek's test (12). The threshold of significant statistical difference was defined as $\mathrm{P}<0.05$.

\section{Results}

Based on the computer and manual cross check strategy, initially 833 potential papers were retrieved. Five hundred twenty four articles were screened after removing the 309 duplicate literatures. On the basis of titles and abstracts, 70 articles were selected for further evaluation. Finally, after reading the full text, 18 eligible literature sources (14 English and four Chinese) that met the inclusion criteria were included in this meta-analysis (Table 2 ) $(2,13-30)$. The results of the selection process are presented in Figure 1 . The quality of included study is shown in Table 3.

In all the included studies $(\mathrm{n}=18)$, the data of rotator cuff injury were acquired with 1.5-T equipment in five studies, and only three studies examined MRI at 3.0 T; four studies did not provide relevant equipment information. A fat saturation T2 sequence was used in six studies. These 18 included studies comprised 1830 patients. The age distribution was reported heterogeneously; the mean age was shown in 16 studies and ranged from 31 to 69 years. Eight of the included studies provided the data of MRI parameters repetition time (TR), and echo time (TE). The above data is displayed in Table 2 .

Of the 18 included studies, 12 reported the accuracy of MRI to assess any rotator cuff tear. The sensitivity (93\%, 95\% CI: 0.91 - 0.95) and specificity (88\%, 95\% CI: 0.84 - 0.91) values of any rotator cuff tears for MRI are displayed in Figure 2. The DOR of any rotator cuff tears by MRI was 96.58 (95\% CI: 46.16 - 202.06).

Of the 18 included studies, 11 reported the accuracy of MRI to assess full-thickness tears. The sensitivity (87\%, 95\% CI: 0.84 - 0.90) and specificity (93\%, 95\% CI: 0.89 - 0.96) value of full-thickness tears for MRI are displayed in Figure 3. The DOR of full-thickness tears by MRI was 128.78 (95\% CI: 63.34 to 261.85).

Seven studies assessed the diagnostic accuracy of partial thickness rotator cuff tears from 560 patients. The sensitivity (80\%, 95\% CI: 0.73 - 0.86) and specificity (92\%, 95\% CI: $0.89-0.94)$ value of partial thickness rotator cuff for MRI are displayed in Figure 4. The DOR of partial thickness rotator cuff by MRI was 36.07 (95\% CI: 7.31 to 177.90).

Overall, the SROC plot (Figure 5) indicated higher diagnostic accuracy for full-thickness tears than partialthickness tears. Besides, the DOR of partial-thickness tears (DOR $=36.07$; 95\% CI: 7.31 to 177.90$)$ was lower than fullthickness tears (DOR $=128.78$; 95\% CI: 63.34 to 261.85), indicating better diagnostic performance for full-thickness than for partial-thickness tears on MRI.

Table 2 shows the results of factors influencing the diagnosis by meta-regression analysis. Meta regression analysis showed that different devices (GE or Philips) do not sig- 

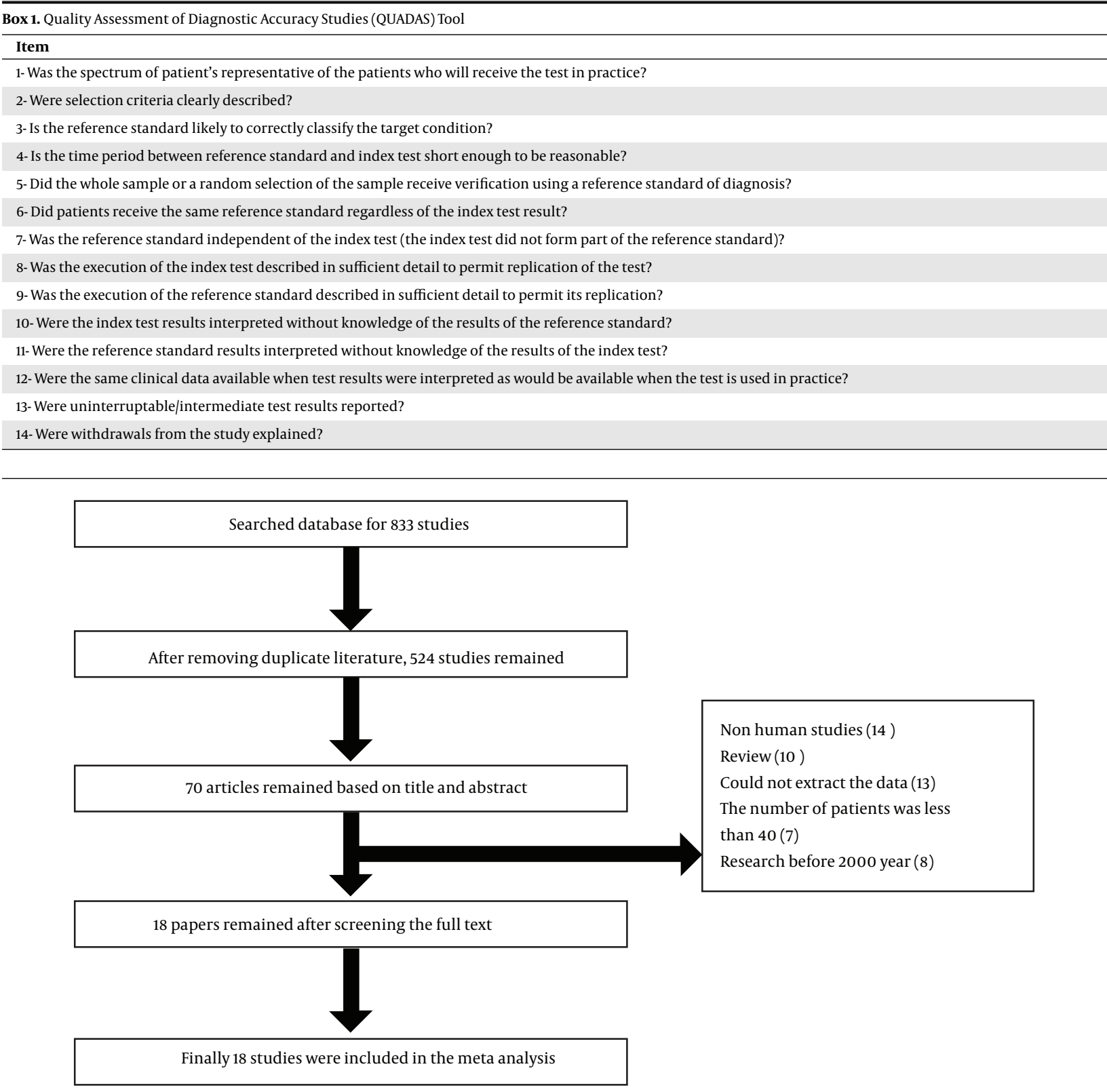

Figure 1. Flow chart of study selection

nificantly affect the diagnosis of rotator cuff injury. Meta regression analysis also identified that Chinese versus English language had no significant effect on diagnostic performance. No correlation between other investigated covariates (patient number, age, and magnetic resonance parameters) and diagnostic performance was observed.

\section{Discussion}

This study was conducted to assess the diagnostic accuracy of magnetic resonance imaging in the evaluation of rotator cuff tears. In our meta-analysis, quality-related problems were identified, and only six of all studies distinguished partial and full-thickness tears. Although the MRI scanning position and parameters were described sufficiently in all studies, several studies had reported the use of fat suppression sequences. Despite the fact that 

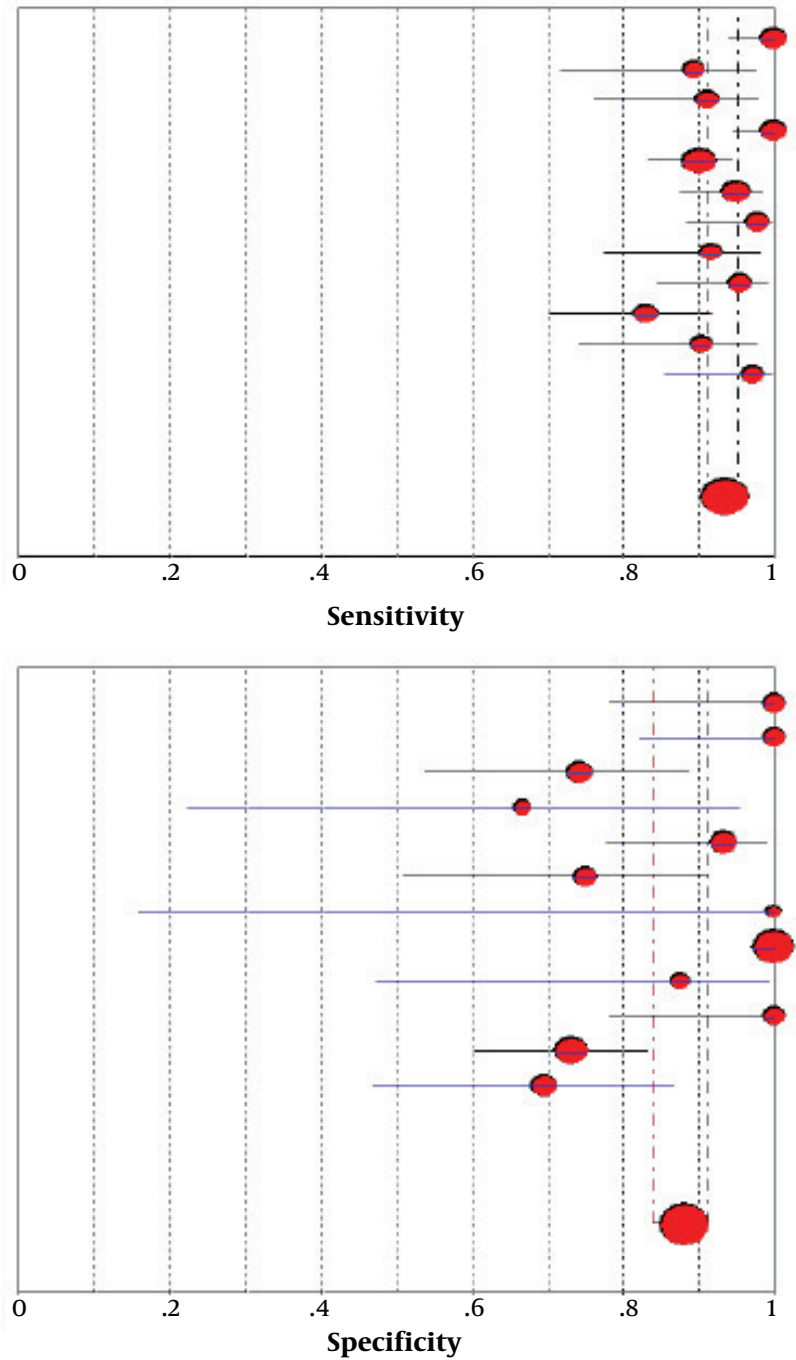

Yamakawa

Shellock

Martin

Teefey

Zlatkin

Lannotti

Lambert

Magee

Jiang

Hitachi

Ostor

Liu

Pooled Sensitivity $=0.93$ (0.91 to 0.95$)$

Chi-square $=31.01 ; \mathrm{df}=11(\mathrm{P}=0.0011)$

Inconsistency (I-square) $=64.5 \%$

\section{Yamakawa}

Shellock

Martin

Teefey

Zlatkin

Lannotti

Lambert

Magee

Jiang

Hitachi

Ostor

Liu
Sensitivity (95\% CI)

$1.00 \quad(0.94-1.00)$

$0.89 \quad(0.72-0.98)$

$0.91 \quad(0.76-0.98)$

$1.00 \quad(0.94-1.00)$

$0.90 \quad(0.84-0.95)$

$0.95 \quad(0.88-0.99)$

$0.98 \quad(0.88-1.00)$

$0.92 \quad(0.78-0.98)$

$0.95 \quad(0.85-0.99)$

$0.83 \quad(070-0.92)$

$0.90 \quad(074-0.98)$

$0.97 \quad(0.85-1.00)$
Specificity (95\% CI)

$1.00 \quad(0.78-1.00)$

$1.00 \quad(0.82-1.00)$

$0.74 \quad(0.54-0.89)$

$0.67 \quad(0.22-0.96)$

$0.93 \quad(0.78-0.99)$

$0.75 \quad(0.51-0.91)$

$1.00 \quad(0.16-1.00)$

$1.00 \quad(0.97-1.00)$

$0.88 \quad(0.47-1.00)$

$1.00 \quad(0.78-1.00)$

$0.73 \quad(0.60-0.83)$

$0.70 \quad(0.47-0.87)$

Pooled specificity $=0.88(0.84$ to 0.91$)$

Chi-square $=67.32 ; \mathrm{df}=11(\mathrm{P}=0.0000)$

Inconsistency (I-square) $=83.7 \%$

Figure 2. Forest plots of pooled sensitivity and specificity for MRI in the diagnosis of any rotator cuff tears (df; degree of freedom, Cl; confidence interval).

Table 1. Results of Meta Regression Analysis

\begin{tabular}{lccc}
\hline \multirow{2}{*}{ Classification of rotator cuff tear } & \multicolumn{3}{c}{ Pvalue } \\
\cline { 2 - 4 } & Scanner & Language & $\mathbf{B}^{\mathbf{a}}$ \\
\hline Partial-thickness tear & 0.5899 & 0.9189 & 0.3449 \\
Full-thickness tear & 0.7984 & 0.6940 & 0.1198 \\
\hline Any tear & 0.4566 & 0.0719 & 0.6645 \\
\hline
\end{tabular}

${ }^{\text {a }}$ Field strength.

the fat suppression sequence displayed that the anatomical structure was slightly worse than T1 weighted image (T1WI), highlighting the characteristics of the water signal, it is more sensitive than the conventional T2 weighted image (T2WI) sequence in identifying rotator cuff tears (31). Because fat suppression sequences affect the diagnosis, application of the fat suppression sequence should be mentioned in the study.

In this meta-analysis, 18 studies involving 984 patients were included. Based on the results of this analysis, the overall sensitivity of MRI for identifying any rotator cuff tear was $93 \%$, a value that was higher than that of fullthickness tears (87\%) and partial thickness tears (80\%). However, the overall specificity of MRI for identifying fullthickness tears (93\%) was higher than that for any rotator cuff tear (88\%). Additionally, the overall area under the 


\begin{tabular}{|c|c|c|c|c|c|c|c|c|}
\hline Study name & Field strength & No. of patient & Mean age & $\mathbf{M} / \mathbf{F}$ & Scanner & TR & TE & QUADAS \\
\hline Guo et al. (29) & NM & 53 & 55 & $41 / 12$ & NM & NM & NM & 8 \\
\hline Shellock et al. (26) & 0.2 & 47 & 52 & $31 / 16$ & GE & 2,200 & 80 & 11 \\
\hline Yamakawa et al. (27) & 0.5 & 58 & 57 & $43 / 15$ & NM & 3,000 & 100 & 9 \\
\hline Martin-Hervas et al. (25) & 0.5 & 61 & NM & $25 / 36$ & Philips & NM & NM & 9 \\
\hline Teefey et al. (22) & 1.5 & 71 & 59 & $41 / 30$ & GE & NM & NM & 10 \\
\hline Zlatkin et al. (23) & 0.2 & 160 & 56 & $91 / 69$ & GE & 2,200 & 80 & 10 \\
\hline Magee (13) & 3 & 150 & 31 & $109 / 41$ & GE & 3,850 & 55 & 11 \\
\hline Hitachi et al. (15) & 1.5 & 68 & 58 & $43 / 25$ & Philips & 3000 & 70 & 10 \\
\hline Iannotti et al. (21) & 1.5 & 106 & NM & NM & NM & NM & NM & 7 \\
\hline Lambert et al. (20) & 3 & 48 & 56 & NM & NM & NM & NM & 9 \\
\hline Vlychou et al. (17) & 1.5 & 56 & 53.7 & $17 / 39$ & SMS & 4000 & 58 & 11 \\
\hline Ostor et al. (14) & NM & 94 & 51 & $56 / 38$ & NM & NM & NM & 9 \\
\hline Adams et al. (16) & NM & 120 & 55 & $75 / 45$ & NM & NM & NM & 7 \\
\hline Magee (19) & 3 & 150 & 55 & $116 / 34$ & GE & 3850 & 55 & 12 \\
\hline Jiang et al. (30) & 0.2 & 52 & 59 & $28 / 24$ & GE & NM & NM & 11 \\
\hline Guo et al. (29) & NM & 59 & 56 & $25 / 34$ & GE & NM & NM & 10 \\
\hline
\end{tabular}

Abbreviations: F, female; M, male; NM, not mentioned; QUADAS, quality assessment of diagnostic accuracy studies; TE, echo time; TR, repetition time.

\begin{tabular}{|c|c|c|c|c|c|c|c|c|c|c|c|c|c|c|c|}
\hline \multirow{2}{*}{ Study name } & \multicolumn{14}{|c|}{ Item of QUADAS tool } & \multirow{2}{*}{ Total score } \\
\hline & 1 & 2 & 3 & 4 & 5 & 6 & 7 & 8 & 9 & 10 & 11 & 12 & 13 & 14 & \\
\hline Guo et al. (29) & $\mathrm{Y}$ & $\mathrm{N}$ & $\mathrm{Y}$ & $\mathrm{N}$ & $\mathrm{Y}$ & $\mathrm{Y}$ & $\mathrm{Y}$ & $\mathrm{N}$ & $\mathrm{Y}$ & $\mathrm{N}$ & $\mathrm{Y}$ & $\mathrm{N}$ & $\mathrm{Y}$ & $\mathrm{N}$ & 8 \\
\hline Shellock et al. (26) & $\mathrm{Y}$ & $\mathrm{Y}$ & Y & $\mathrm{Y}$ & $\mathrm{N}$ & $\mathrm{Y}$ & $\mathrm{Y}$ & Y & $\mathrm{N}$ & $\mathrm{Y}$ & $\mathrm{Y}$ & $\mathrm{N}$ & $\mathrm{Y}$ & $\mathrm{Y}$ & 11 \\
\hline Yamakawa et al. (27) & $\mathrm{Y}$ & Y & $\mathrm{Y}$ & $\mathrm{N}$ & $\mathrm{Y}$ & $\mathrm{Y}$ & $\mathrm{N}$ & $\mathrm{Y}$ & $\mathrm{Y}$ & $\mathrm{N}$ & $\mathrm{Y}$ & $\mathrm{N}$ & $\mathrm{Y}$ & $\mathrm{N}$ & 9 \\
\hline Martin-Hervas et al. (25) & $\mathrm{Y}$ & $\mathrm{Y}$ & Y & $\mathrm{Y}$ & $\mathrm{N}$ & $\mathrm{Y}$ & $\mathrm{N}$ & $\mathrm{Y}$ & $\mathrm{Y}$ & $\mathrm{N}$ & $\mathrm{Y}$ & $\mathrm{N}$ & $\mathrm{N}$ & $\mathrm{Y}$ & 9 \\
\hline Chang et al. (24) & $\mathrm{Y}$ & Y & Y & $\mathrm{Y}$ & $\mathrm{N}$ & $\mathrm{Y}$ & $\mathrm{N}$ & Y & $\mathrm{N}$ & $\mathrm{Y}$ & $\mathrm{Y}$ & $\mathrm{Y}$ & $\mathrm{N}$ & $\mathrm{Y}$ & 10 \\
\hline Teefey et al. (22) & $\mathrm{Y}$ & Y & $\mathrm{Y}$ & $\mathrm{Y}$ & $\mathrm{Y}$ & $\mathrm{N}$ & $\mathrm{Y}$ & $\mathrm{Y}$ & $\mathrm{N}$ & $\mathrm{Y}$ & $\mathrm{Y}$ & $\mathrm{Y}$ & $\mathrm{N}$ & $\mathrm{N}$ & 10 \\
\hline Zlatkin (23) & $\mathrm{Y}$ & $\mathrm{Y}$ & Y & $\mathrm{N}$ & $\mathrm{Y}$ & $\mathrm{N}$ & $\mathrm{Y}$ & $\mathrm{Y}$ & $\mathrm{N}$ & $\mathrm{Y}$ & $\mathrm{Y}$ & $\mathrm{Y}$ & $\mathrm{N}$ & $\mathrm{Y}$ & 10 \\
\hline Magee (13) & $\mathrm{Y}$ & Y & $\mathrm{Y}$ & $\mathrm{Y}$ & $\mathrm{Y}$ & $\mathrm{N}$ & $\mathrm{Y}$ & $\mathrm{Y}$ & $\mathrm{N}$ & $\mathrm{Y}$ & $\mathrm{Y}$ & $\mathrm{Y}$ & $\mathrm{N}$ & $\mathrm{Y}$ & 11 \\
\hline Hitachic(15) & $\mathrm{Y}$ & $\mathrm{Y}$ & $\mathrm{Y}$ & $\mathrm{Y}$ & $\mathrm{Y}$ & $\mathrm{N}$ & $\mathrm{Y}$ & $\mathrm{Y}$ & $\mathrm{N}$ & $\mathrm{N}$ & $\mathrm{Y}$ & $\mathrm{Y}$ & $\mathrm{N}$ & $\mathrm{Y}$ & 10 \\
\hline Iannotti (21) & Y & Y & Y & $\mathrm{N}$ & $\mathrm{Y}$ & $\mathrm{N}$ & $\mathrm{Y}$ & $\mathrm{N}$ & $\mathrm{N}$ & $\mathrm{Y}$ & $\mathrm{N}$ & $\mathrm{N}$ & $\mathrm{Y}$ & $\mathrm{N}$ & 7 \\
\hline Lambert (20) & $\mathrm{Y}$ & Y & $\mathrm{Y}$ & $\mathrm{N}$ & $\mathrm{Y}$ & $\mathrm{N}$ & $\mathrm{Y}$ & $\mathrm{N}$ & $\mathrm{Y}$ & $\mathrm{Y}$ & $\mathrm{N}$ & $\mathrm{Y}$ & $\mathrm{Y}$ & $\mathrm{N}$ & 9 \\
\hline Naqvi (18) & $\mathrm{Y}$ & Y & $\mathrm{Y}$ & $\mathrm{N}$ & $\mathrm{Y}$ & $\mathrm{N}$ & $\mathrm{Y}$ & $\mathrm{N}$ & $\mathrm{Y}$ & $\mathrm{Y}$ & $\mathrm{N}$ & $\mathrm{N}$ & $\mathrm{Y}$ & $\mathrm{N}$ & 8 \\
\hline Vlychou (17) & $\mathrm{Y}$ & $\mathrm{Y}$ & Y & $\mathrm{Y}$ & $\mathrm{Y}$ & $\mathrm{N}$ & $\mathrm{Y}$ & $\mathrm{Y}$ & $\mathrm{N}$ & $\mathrm{Y}$ & $\mathrm{Y}$ & $\mathrm{Y}$ & $\mathrm{N}$ & $\mathrm{Y}$ & 11 \\
\hline Ostor et al. (14) & $\mathrm{Y}$ & $\mathrm{Y}$ & $\mathrm{Y}$ & $\mathrm{N}$ & $\mathrm{Y}$ & $\mathrm{Y}$ & $\mathrm{N}$ & $\mathrm{Y}$ & $\mathrm{Y}$ & $\mathrm{N}$ & $\mathrm{Y}$ & $\mathrm{N}$ & $\mathrm{Y}$ & $\mathrm{N}$ & 9 \\
\hline Adams et al. (16) & $\mathrm{Y}$ & $\mathrm{Y}$ & $\mathrm{Y}$ & $\mathrm{N}$ & $\mathrm{Y}$ & $\mathrm{N}$ & $\mathrm{Y}$ & $\mathrm{N}$ & $\mathrm{Y}$ & $\mathrm{Y}$ & $\mathrm{N}$ & $\mathrm{N}$ & $\mathrm{N}$ & $\mathrm{N}$ & 7 \\
\hline Magee (19) & $\mathrm{Y}$ & $\mathrm{Y}$ & $\mathrm{Y}$ & $\mathrm{Y}$ & $\mathrm{Y}$ & $\mathrm{Y}$ & $\mathrm{Y}$ & $\mathrm{Y}$ & $\mathrm{N}$ & $\mathrm{Y}$ & $\mathrm{Y}$ & $\mathrm{Y}$ & $\mathrm{N}$ & $\mathrm{Y}$ & 12 \\
\hline Jiang et al. (30) & $\mathrm{Y}$ & Y & $\mathrm{Y}$ & $\mathrm{N}$ & $\mathrm{Y}$ & $\mathrm{Y}$ & $\mathrm{Y}$ & $\mathrm{Y}$ & $\mathrm{Y}$ & $\mathrm{Y}$ & $\mathrm{Y}$ & $\mathrm{N}$ & $\mathrm{Y}$ & $\mathrm{N}$ & 11 \\
\hline Liu et al. (2) & $\mathrm{Y}$ & $Y$ & $\mathrm{Y}$ & $\mathrm{Y}$ & $\mathrm{N}$ & $\mathrm{Y}$ & $\mathrm{Y}$ & $\mathrm{Y}$ & $\mathrm{N}$ & $\mathrm{Y}$ & $Y$ & $\mathrm{Y}$ & $\mathrm{N}$ & $\mathrm{N}$ & 10 \\
\hline
\end{tabular}

${ }^{a}$ If the published research meets this requirement, fill in the form Yes $(\mathrm{Y})$, otherwise fill in No $(\mathrm{N})$.

curve(AUC) of MRI for identifying full-thickness tears (96\%) was close to that of any rotator cuff tear and was much higher than that for partial tears (86\%). The threshold effects were not significant in this meta-analysis.

A number of studies have been carried out to evaluate MRI in detecting rotator cuff tears $(4,8,16,18)$. Liu sum- marized the specificity and sensitivity of MRI as $94 \%$ and 88.3\% for rotator cuff tears (2). Naqvi et al. (18) reviewed 91 consecutive cases, the pooled estimates of SEN and SPE for MRI were $91 \%$ and $84 \%$, respectively. The SEN (83\%) of partial-thickness tears was lower than full-thickness tears (85\%), which was reported by Yamakawa et al. (27). There 

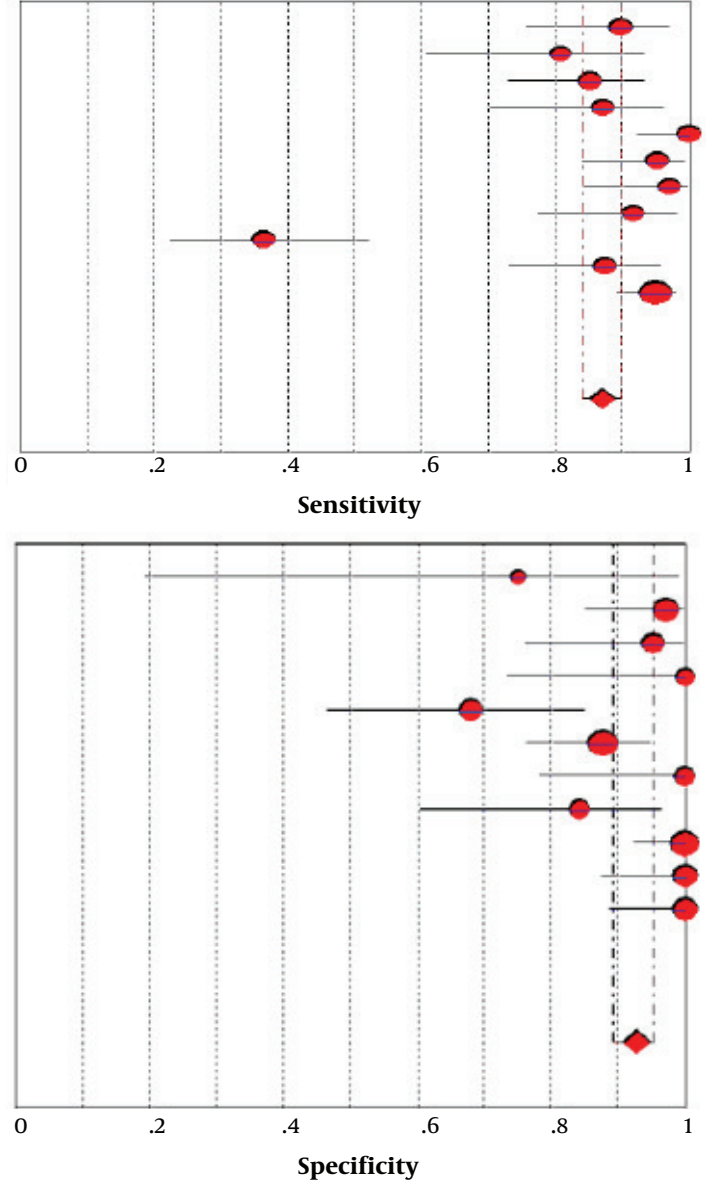

Sensitivity (95\% CI)

$0.90 \quad(0.76-0.97)$

$0.81(0.61-0.93)$

$0.85 \quad(0.73-0.93)$

$0.87 \quad(0.70-0.96)$

$1.00 \quad(0.92-1.00)$

$0.95 \quad(0.84-0.99)$

$0.97 \quad(0.84-1.00)$

$0.92 \quad(0.78-0.98)$

$0.36(0.22-0.52)$

$0.88 \quad(0.73-0.96)$

$0.95 \quad(0.89-0.98)$
Pooled Sensitivity $=0.87$ (0.84 to 0.90$)$ Chi-square $=91.52 ; \mathrm{df}=10(\mathrm{p}=0.0000)$ Inconsistency $(\mathrm{I}$-square $)=89.1 \%$

Guo

Martin

Yamakawa

Chang

Teefey

Lannotti

Lambert

Naqvi

Adams

Hitachi

Magee

Pooled Specificity $=0.93$ (0.89 to 0.96 )

Chi-square $=39.15 ; \mathrm{df}=10(\mathrm{p}=0.0000)$

Inconsistency (I-square) $=74.5 \%$

Figure 3. Forest plots of pooled sensitivity and specificity for MRI in the diagnosis of full thickness rotator cuff tears (df; degree of freedom, CI; confidence interval).

was a tendency towards greater accuracy in the diagnosis of full-thickness tears compared to partial-thickness tears (26). These results were consistent with our conclusion.

A homogeneity test of any rotator cuff tear showed in Figure 2 with sensitivity of $\mathrm{I}^{2}=64.5 \%$ and specificity of $\mathrm{I}^{2}=$ 83.7\%. Notable heterogeneities were also presented in the diagnosis of full-thickness tear with sensitivity of $\mathrm{I}^{2}=89 \%$ and specificity of $\mathrm{I}^{2}=74 \%$. In this meta-analysis, the Spearman correlation coefficient was $0.329(P=0.258)$, indicating that the heterogeneity was unlikely to be attributable to the threshold effect among eligible articles. We performed meta-regression analysis to understand the significant potential other factors had in affecting heterogeneity among individual studies. No correlation between covariates and diagnostic performance was observed.

Several meta-analyses have been reported in the past few years $(8,9,28)$. Our validation result is more convincing than that in the previous meta-analysis. First, our vali- dation result could provide more comprehensive data for diagnosis research, such as the sensitivity and specificity of any rotator cuff tear and results of factors influencing the diagnosis. Second, as far as we are concerned, the present study has a larger sample to increase the reliability of the study. Third, Lenza8 only analyzed several retrospective studies prospective studies were not included in the validation test; thus, publication bias may exist in their study. Only Smith et al. (9) reported sub-group analysis assessing field strength, considering 3T MRI showed excellent performance in the diagnosis of rotator cuff tears compared with 1.5T MRI, while we did not perform subgroup analysis. In addition, we identified the correlation between the factors and diagnostic performance by meta-regression analysis. The QUADAS score of the 10/18 articles exceeded 10, further showing that the high quality of our literature was included.

There are several shortcomings in our study. First, as 


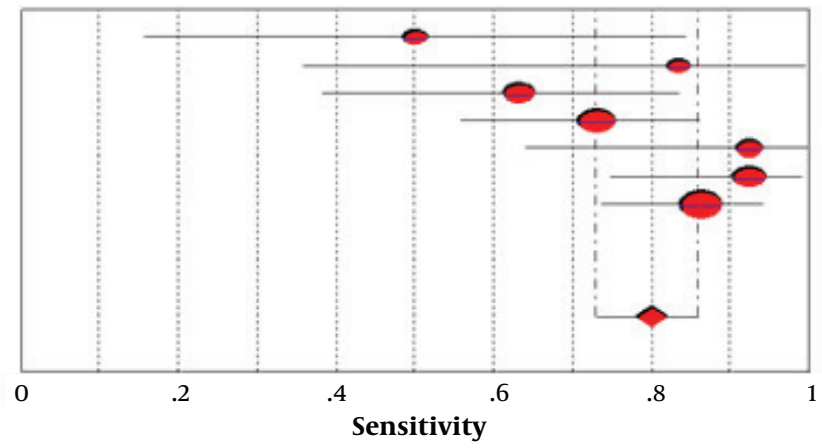

Martin

Yamakawa

Teefey

Lannotti

Lambert

Magee

Vlychou

Pooled Sensitivity $=0.80(0.73$ to 0.86$)$

Chi-square $=13.49 ; \mathrm{df}=6(\mathrm{p}=0.0358)$

Inconsistency (I-square $)=55.5 \%$

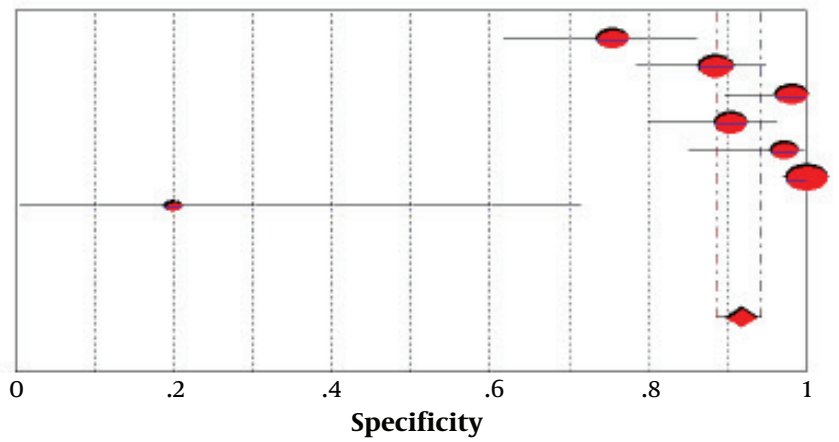

Martin

Yamakawa

Teefey

Lannotti

Lambert

Magee

Vlychou

Pooled Specificity $=0.92(0.89$ to 0.94$)$

Chi-square $=55.91 ; \mathrm{df}=6(\mathrm{p}=0.000)$

Inconsistency (I-square) $=89.3 \%$
A

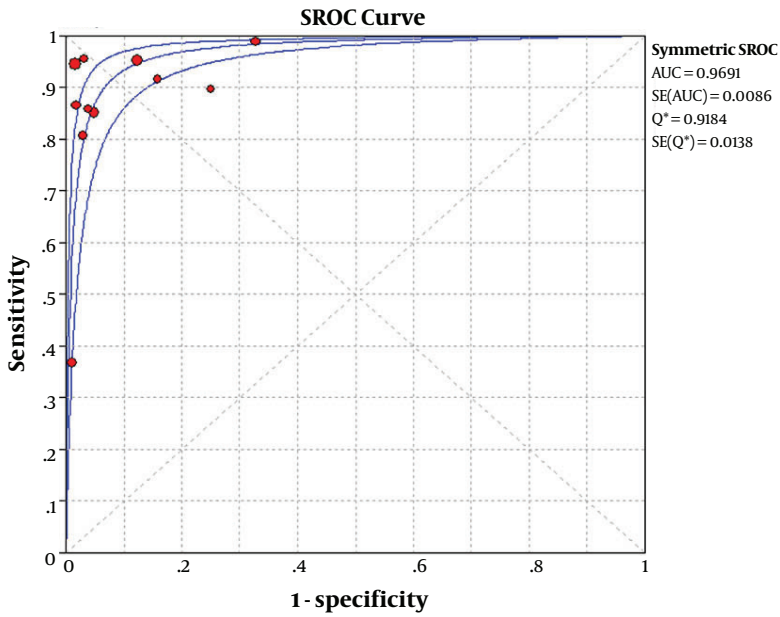

B

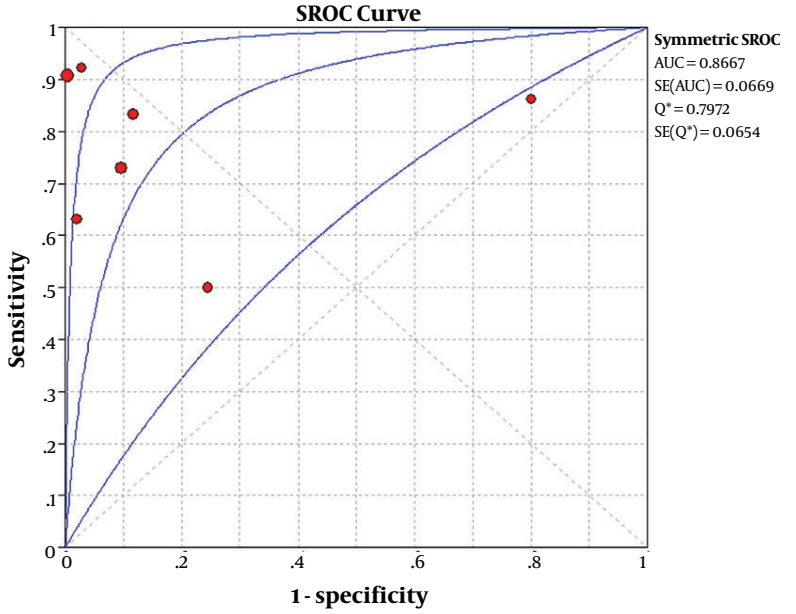

Figure 5. Pooled area under the curve (AUC) of summary receiver-operating characteristic (SROC) for MRI in the diagnosis of A, Full thickness tears and B, Partial thickness rotator cuff tears. Q* statistic denotes the points with the same sensitivity and specificity (SE; standard error).

described above, there was no notable threshold effect, and significant publication bias has not been found in our study. Second, 13 out of 18 studies were retrospective.
Therefore, the pooled diagnostic accuracy might have been overestimated. These results were consistent with the recent meta-analysis. Third, different patient selection crite- 
ria of studies could result in inconsistent results. Larger and more obvious tears were always resulting from traumatic injuries. The patient's age was also a cause of heterogeneity. Although our study found no significant effect of field strength on the diagnostic efficiency, we suspect that different sequences and parameters affect our conclusions $(32,33)$. Given this, further large sample studies are needed, optimization of parameters and image technology are helpful to diagnose rotator cuff tears accurately.

In conclusion, the above evidence in this meta-analysis showed that MRI had excellent performance on the diagnosis of rotator cuff tears. It can accurately assess the extent of rotator cuff tears, provide help for clinical treatment, and ultimately make patients receive timely and correct treatment. If the MRI cannot accurately distinguish the fullthickness rotator cuff tears from partial tears, angiography should be used as an auxiliary diagnostic method.

\section{Footnotes}

Authors' Contributions: Zhanqiu Wang and Wen-Fei Li were responsible for the idea of the article. Tao Chen, Tahir Mehmood Shakir and Yuemei Zhao collected and analyzed data. Chen Niu and Zhanqiu Wang finished the initial manuscript. All authors approved the final version of the manuscript.

Conflict of Interests: All authors have no funding and conflict of interests to disclose.

Financial Disclosure: None declared.

Funding/Support: No funding was received.

\section{References}

1. Ostor AJ, Richards CA, Prevost AT, Speed CA, Hazleman BL. Diagnosis and relation to general health of shoulder disorders presenting to primary care. Rheumatology (Oxford). 2005;44(6):800-5. doi: 10.1093/rheumatology/keh598. [PubMed: 15769790].

2. Liu JC, Chen JH, Huang H, Wang TB, Jiang BG. The preliminary comparative study between MRI and arthroscopy manifestation for rotator cuff injury. Chinese J Shoulder Elbow (Electronic Edition). 2013:36-9.

3. Ruotolo C, Nottage WM. Surgical and nonsurgical management of rotator cuff tears. Arthroscopy. 2002;18(5):527-31. doi: 10.1053/jars.2002.31707. [PubMed: 11987065].

4. Freygant M, Dziurzynska-Bialek E, Guz W, Samojedny A, Golofit A, Kostkiewicz A, et al. Magnetic resonance imaging of rotator cuff tears in shoulder impingement syndrome. Pol J Radiol. 2014;79:3917. doi: 10.12659/PJR.890541. [PubMed: 25374626]. [PubMed Central: PMC4220601].

5. Codsi MJ, Rodeo SA, Scalise JJ, Moorehead TM, Ma CB. Assessment of rotator cuff repair integrity using ultrasound and magnetic resonance imaging in a multicenter study. J Shoulder Elbow Surg. 2014;23(10):1468-72. doi:10.1016/j.jse.2014.01.045. [PubMed: 24751529].

6. Honda H, Morihara T, Arai Y, Horii M, Ito H, Furukawa R, et al. Clinical application of radial magnetic resonance imaging for evaluation of rotator cuff tear. Orthop Traumatol Surg Res. 2015;101(6):715-9. doi: 10.1016/j.otsr.2015.06.007. [PubMed: 26315347].
7. Watanabe T, Terabayashi N, Fukuoka D, Murakami H, Ito H, Matsuoka T, et al. A pilot study to assess Fatty infiltration of the supraspinatus in patients with rotator cuff tears: Comparison with magnetic resonance imaging. Ultrasound Med Biol. 2015;41(6):1779-83. doi: 10.1016/j.ultrasmedbio.2015.01.013. [PubMed: 25746906].

8. Lenza M, Buchbinder R, Takwoingi Y, Johnston RV, Hanchard NC, Faloppa F. Magnetic resonance imaging, magnetic resonance arthrography and ultrasonography for assessing rotator cuff tears in people with shoulder pain for whom surgery is being considered. Cochrane Database Syst Rev. 2013;(9). CD009020. doi: 10.1002/14651858.CD009020.pub2. [PubMed: 24065456].

9. Smith TO, Daniell H, Geere JA, Toms AP, Hing CB. The diagnostic accuracy of MRI for the detection of partial- and full-thickness rotator cuff tears in adults. Magn Reson Imaging. 2012;30(3):336-46. doi: 10.1016/j.mri.2011.12.008. [PubMed: 22260933].

10. Whiting P, Rutjes AW, Reitsma JB, Bossuyt PM, Kleijnen J. The development of QUADAS: A tool for the quality assessment of studies of diagnostic accuracy included in systematic reviews. BMC Med Res Methodol. 2003;3:25. doi: 10.1186/1471-2288-3-25. [PubMed: 14606960]. [PubMed Central: PMC305345].

11. Lijmer JG, Bossuyt PM, Heisterkamp SH. Exploring sources of heterogeneity in systematic reviews of diagnostic tests. Stat Med. 2002;21(11):1525-37. doi: 10.1002/sim.1185. [PubMed: 12111918].

12. Egger M, Davey Smith G, Schneider M, Minder C. Bias in metaanalysis detected by a simple, graphical test. BMJ.1997;315(7109):62934. [PubMed: 9310563]. [PubMed Central: PMC2127453].

13. Magee T. MR versus MR arthrography in detection of supraspinatus tendon tears in patients without previous shoulder surgery. Skeletal Radiol. 2014;43(1):43-8. doi: 10.1007/s00256-013-1745-x. [PubMed: 24122001].

14. Ostor AJ, Richards CA, Tytherleigh-Strong G, Bearcroft PW, Prevost AT, Speed CA, et al. Validation of clinical examination versus magnetic resonance imaging and arthroscopy for the detection of rotator cufflesions. Clin Rheumatol.2013;32(9):1283-91. doi:10.1007/s10067013-2260-0. [PubMed: 23636792].

15. Hitachi S, Takase K, Tanaka M, Tojo Y, Tabata S, Majima K, et al. Highresolution magnetic resonance imaging of rotator cuff tears using a microscopy coil: Noninvasive detection without intraarticular contrast material. Jpn J Radiol. 2011;29(7):466-74. doi: 10.1007/s11604-0110583-9. [PubMed: 21882088].

16. Adams CR, Schoolfield JD, Burkhart SS. Accuracy of preoperative magnetic resonance imaging in predicting a subscapularis tendon tear based on arthroscopy. Arthroscopy. 2010;26(11):1427-33. doi: 10.1016/j.arthro.2010.02.028. [PubMed: 20875724].

17. Vlychou M, Dailiana Z, Fotiadou A, Papanagiotou M, Fezoulidis IV, Malizos K. Symptomatic partial rotator cuff tears: diagnostic performance of ultrasound and magnetic resonance imaging with surgical correlation. Acta Radiol. 2009;50(1):101-5. doi: 10.1080/02841850802600764. [PubMed:19052931].

18. Naqvi GA, Jadaan M, Harrington P. Accuracy of ultrasonography and magnetic resonance imaging for detection of full thickness rotator cuff tears. Int J Shoulder Surg. 2009;3(4):94-7. doi: 10.4103/09736042.63218. [PubMed: 20532011]. [PubMed Central: PMC2878704].

19. Magee T.3-T MRI of the shoulder: Is MR arthrography necessary? AJR Am J Roentgenol. 2009;192(1):86-92. doi: 10.2214/AJR.08.1097. [PubMed: 19098184].

20. Lambert A, Loffroy R, Guiu B, Mejean N, Lerais JM, Cercueil JP, et al. [Rotator cuff tears: Value of 3.0T MRI]. J Radiol. 2009;90(5 Pt 1):583-8. French. [PubMed: 19503046].

21. Iannotti JP, Ciccone J, Buss DD, Visotsky JL, Mascha E, Cotman K, et al. Accuracy of office-based ultrasonography of the shoulder for the diagnosis of rotator cuff tears. J Bone Joint Surg Am. 2005;87(6):1305-11. doi: 10.2106/JBJS.D.02100. [PubMed: 15930541]. 
22. Teefey SA, Rubin DA, Middleton WD, Hildebolt CF, Leibold RA, Yamaguchi K. Detection and quantification of rotator cuff tears. Comparison of ultrasonographic, magnetic resonance imaging, and arthroscopic findings in seventy-one consecutive cases.J Bone Joint Surg Am. 2004;86-A(4):708-16. [PubMed: 15069134].

23. Zlatkin MB, Hoffman C, Shellock FG. Assessment of the rotator cuff and glenoid labrum using an extremity MR system: MR results compared to surgical findings from a multi-center study. J Magn Reson Imaging. 2004;19(5):623-31. doi: 10.1002/jmri.20040. [PubMed: 15112313].

24. Chang CY, Wang SF, Chiou HJ, Ma HL, Sun YC, Wu HD. Comparison of shoulder ultrasound and MR imaging in diagnosing full-thickness rotator cuff tears. Clin Imaging. 2002;26(1):50-4. [PubMed: 11814754].

25. Martin-Hervas C, Romero J, Navas-Acien A, Reboiras JJ, Munuera L. Ultrasonographic and magnetic resonance images of rotator cuff lesions compared with arthroscopy or open surgery findings. J Shoulder Elbow Surg. 2001;10(5):410-5. doi: 10.1067/mse.2001.116515. [PubMed 11641696].

26. Shellock FG, Bert JM, Fritts HM, Gundry CR, Easton R, Crues J3. Evaluation of the rotator cuff and glenoid labrum using a 0.2-Tesla extremity magnetic resonance (MR) system: MR results compared to surgical findings. J Magn Reson Imaging. 2001;14(6):763-70. [PubMed 11747034].

27. Yamakawa S, Hashizume H, Ichikawa N, Itadera E, Inoue H. Comparative studies of MRI and operative findings in rotator cuff tear. Acta
Med Okayama. 2001;55(5):261-8. doi: 10.18926/AMO/32019. [PubMed: 11688948].

28. de Jesus JO, Parker L, Frangos AJ, Nazarian LN. Accuracy of MRI, MR arthrography, and ultrasound in the diagnosis of rotator cuff tears: A meta-analysis. AJR Am J Roentgenol. 2009;192(6):1701-7. doi: 10.2214/AJR.08.1241. [PubMed: 19457838]

29. Guo A, Fujita K, Mizuno K. Diagnostic value of arthrography and MRI in rotator cuff tears. Chinese J Surg. 2000;4:22-4.

30. Jiang ZY, Lu Y, He GQ, Liu YP. Diagnostic value of low-field MRI system in rotator cuff injuries. Chinese J Gen Pract. 2010;12:1608-9.

31. Kijowski R, Farber JM, Medina J, Morrison W, Ying J, Buckwalter K. Comparison of fat-suppressed T2-weighted fast spin-echo sequence and modified STIR sequence in the evaluation of the rotator cuff tendon. AJR Am J Roentgenol. 2005;185(2):371-8. doi: 10.2214/ajr.185.2.01850371. [PubMed: 16037507].

32. Choo HJ, Lee SJ, Kim OH, Seo SS, Kim JH. Comparison of threedimensional isotropic T1-weighted fast spin-echo MR arthrography with two-dimensional MR arthrography of the shoulder. Radiology. 2012;262(3):921-31. doi: 10.1148/radiol.11111261. [PubMed: 22267587].

33. Lee JH, Yoon YC, Jee S, Kwon JW, Cha JG, Yoo JC. Comparison of three-dimensional isotropic and two-dimensional conventional indirect MR arthrography for the diagnosis of rotator cuff tears. Korean J Radiol. 2014;15(6):771-80. doi: 10.3348/kjr.2014.15.6.771. [PubMed: 25469089]. [PubMed Central: PMC4248633]. 